\section{On dependencies between architecture and media: considering the remote work}

\author{
Mike Christenson, \\ North Dakota State University
}

\begin{abstract}
To consider architecture as a communicative medium requires acknowledgment of the necessity of mediating artifacts such as drawings, models, and photographs, insofar as these artifacts provide structure for communication and discourse. In this essay, I examine the criticality of mediating artifacts to architecture's communicative potential by proposing a tactical identity between the act of architectural design and the study of architectural precedent. In both situations, mediating artifacts incorporate decisions and assumptions about how architectural significance should be communicated.

I propose two hypotheses as frames within which to discuss architecture's dependence on mediating artifacts. First, the Neutral Frame hypothesis suggests that significant attributes of a work of architecture are capable of disclosure regardless of the medium through which these attributes are "filtered." By contrast, the Production Bias hypothesis holds that significant attributes of a work of architecture can be identified as unique to a medium of investigation, and furthermore, that in some cases it may not be possible to disclose a given attribute by any other means. By considering existing photographs of a completed work of architecture (Crown Hall in Chicago, Illinois) in two ways, first through computer-aided manipulation and second by diagramming superimposed fields-of-view of photographs from two distinct sources, I suggest that the Production Bias hypothesis is the better explanation of architecture's relationship to mediating artifacts.
\end{abstract}

\section{I ntroduction}

\subsection{Remote works and tactical identity}

Both architectural design and precedent study are concerned with the remote work of architecture. A remote work is one which is accessed or understood through mediating artifacts such as drawings, models, photographs, text, or digital simulations. The object of architectural design is a remote work prior to its construction: it cannot be directly inhabited until built; the object of precedent study is a remote work whenever the study is undertaken from a distant position. As William Porter has suggested, mediating artifacts are objects which may not be "integral to the production of the building, yet are integral to the cultivation of ideas which relate to the building." 1 That this is so is obvious in the case of design, when architects create artifacts to "cultivate ideas" as well as to predict the anticipated form of the building. That mediating artifacts are necessary to precedent study is not so obvious; precedent study can include direct ("unmediated") experience of a work of architecture, but the need to record observations and to disseminate results points to the necessity of mediating artifacts.

These observations suggest the possibility of a tactical identity between the act of architectural design and the study of architectural precedent. Specifically, though the strategic aims of design and precedent study may differ (design is "synthetic" while precedent study is "analytic"), ${ }^{2}$ their tactics are identical, insofar as both depend on the persistent, iterative production of drawings, models, and photographs.

\subsection{Architectural significance}

Does a work of architecture's potential to communicate its own significance - its "meaning" in a cultural context - depend on a medium other than itself as a built work? Are mediating artifacts necessary to communicate the significance of a work of architecture? The following sections of this paper introduce two hypotheses as possible frameworks for evaluating this question. First, the Neutral Frame hypothesis is introduced, arguing that significant attributes of a completed work of architecture are capable of disclosure regardless of the medium through which these attributes are "filtered." By contrast, the Production Bias hypothesis is introduced to argue that significant attributes of a completed work of architecture can be identified uniquely with a medium of investigation, and furthermore, that in some cases it may not be possible to disclose a given attribute by any other means. The two hypotheses are not equal and therefore not precisely opposed; nevertheless, each constitutes a distinct framework for understanding the relationships between mediating artifacts and architecture's communicative potential.

\section{The Neutral Frame hypothesis}

The Neutral Frame (NF) hypothesis is proposed as follows:

Works of architecture possess specific attributes, the significance of which can be communicated regardless of the medium through which those attributes are filtered. 
The NF hypothesis holds that architectural mediating artifacts have no significant effect on architecture's communicative potential; the "message" of a work of architecture - whatever it may be - is not affected by the medium through which it is communicated.

\subsection{Media as neutral frames}

For over twenty-five years, instructional technology literature has considered the "media-methods debate" as a central topic. ${ }^{3}$ Richard E. Clark crystallized the debate by claiming that "[t]he best current evidence is that media are mere vehicles that deliver instruction but do not influence student achievement any more than the truck that delivers our groceries causes changes in our nutrition." ${ }^{4}$ Clark argued that media selection in instructional technology should be concerned with identifying the most economical form for message delivery. In a later paper, Clark offered a "replacability challenge," which proposed that for any given set of learning gains, researchers should be able to identify a distinctly different instructional medium resulting in the same gains. ${ }^{5}$ Clark's replacability challenge can be seen as a general case of the NF hypothesis: supposing that in the study of architectural precedent, or in the act of architectural design, a set of significant attributes are identified by means of a specific medium of investigation (e. g., architectural drawings), Clark's replacability challenge suggests that these attributes could be communicated through many other media, and perhaps more efficiently.

Roger H. Clark (no relation to Richard E. Clark) and Michael Pause, in Precedents in Architecture, originally published in 1985, proposed "a way of thinking about architecture that emphasizes what is in essence the same, rather than different ... we hope to pursue archetypal ideas that might aid in the generation of architectural form" (emphasis added). ${ }^{6}$ The authors explicitly sought to "develop analysis as a tool for design." Clark and Pause set forth a framework consisting of twelve categories, graphically presented in the book as gridded pages filled with categorized diagrams for each of sixty-four buildings. ${ }^{7}$ The implication of their presentation is that the framework was applicable to any work of architecture. Thus, their approach appears to offer support to the NF hypothesis. However, idiosyncrasies and exceptions to their framework exist, leaving open whether a more robust classification scheme could be developed as a truly neutral frame for communicating architectural significance. ${ }^{8}$

\subsection{Architectural photography}

The architectural photograph understood traditionally - as a physical artifact produced by means of a film camera and darkroom technologies - served in the past as an ad hoc means of distinguishing between built and unbuilt architecture. Generally speaking, a traditional photograph of a work of architecture indicated that the work was built; unbuilt architecture could not be photographed. However, the advent of digital technology since the early 1980 s made it possible to create photographic images which are capable of being mistaken for photographs, even by experts; 9 in other words, digital technology eliminated the possibility that a photograph could be used as a means to distinguish between built and unbuilt architecture. Photographs (or more generally, "photographic images") are now used in tactically identical ways in both architectural design and the study of architectural precedent - which promotes the possibility that constructed artifacts can be understood as neutral frames for communication. That this situation demands further critical attention is obvious given the advent of increasingly powerful digital tools which accurately simulate a wide range of sensory perceptions. Adi Shamir Zion describes a view of digital technology in which "the stereographic image presented in the automation of pictorial representation [i. e., digitally constructed 'virtual reality'] is realistically known, but it is neither mediated nor abstracted" (emphasis added)..$^{10}$ If this view - which appears to offer support for the NF hypothesis is shown to be correct, then "virtual reality" would constitute a truly transparent representational technology, one in which architecture's communicative potential is not affected by the medium of communication.

\section{The Production Bias hypothesis}

The Production Bias (PB) hypothesis is proposed as follows:

Works of architecture possess specific attributes, the significance of which is uniquely revealed through specific media.

Considered broadly, the PB hypothesis holds that if architecture is acknowledged to have a communicative potential, that potential is achievable only through the production and dissemination of architectural mediating artifacts.

The PB hypothesis is framed as a distillation of the positions and claims of several authors, as detailed in the following section.

\subsection{Literature review: supporting claims}

The assumption that architectural mediating artifacts have a "direct and essential impact"11 on the production of architecture, enjoys wide acceptance within contemporary 
architectural literature - at least insofar as architectural outcome is understood to refer to the production of new architecture. ${ }^{12}$

Mark Hewitt's 1985 proposal for a historical study of architectural drawing took as an assumption the central role of drawings to architectural conception, using Borromini as an example. "Drawings and mental pictures," according to Hewitt, "are clearly related, as is the order in which drawings are made and the relative importance of aspects of the building which they represent." 13 A year later, Norman Crowe and Steven Hurtt acknowledged a central role for mediating artifacts in study: "...[v]isual notations and analytical sketches," they wrote, "are very much like the kinds of drawings that one makes in the design process itself." 14

David Leatherbarrow established a media basis for the assumption of tactical identity between architectural design and the study of architectural precedent when he wrote that "... the purpose of architectural drawings is to discover and disclose aspects of the world that are not immediately apparent and never will be." 15 And lain Borden recently wrote that "[a]rchitecture does not give up its meaning easily - it is not a text, and has no voice. It cannot speak. Its histories therefore have to be constructed." 16

Robert Kozma, in responding to arguments made by Richard Clark (see section 2.1 above), argued that learning is fundamentally a constructive process. ${ }^{17}$ Kozma's consistent position has been that specific methods of inquiry and instruction derive from the capabilities of a given medium. Kozma's position is therefore generally equivalent to the PB hypothesis, which supposes that specific attributes of architecture are uniquely capable of being revealed through specific media.

Bruno Zevi's essay "Representation of Space" is framed to demonstrate the inadequacy of traditional modes of representation, such as the plan, in reflecting upon the experience of space, and in favor of modes of representation approaching full sensory simulation (see section 2.2 above). ${ }^{18}$ But because Zevi's drawings of St. Peter's in Rome reveal specific understandings of architecture which relate to the experience of space without attempting to simulate it, his essay implies that direct experience cannot alone, in the absence of architectural mediating artifacts, constitute a mode of communication.

Donald Schön's work is often cited in favor of the iterative character of architectural design; his position is that designers "reflect-in-action" or learn from intermediary artifacts. Schön's work, with few exceptions, focuses on reflection-in-action as it relates to architecture in a state of production instead of already-built architecture. Two exceptions are, first, his references to site contours in excerpts from recorded discussions in the architecture studio and second, his discussion of the "Library entrance exercise" designed by William Porter. ${ }^{19}$ In this exercise, students interpreted an existing work of architecture through an outline floor plan in order to study possibilities for building entrance locations. Schön and Wiggins offered a critical comment on the possibility of reflection-in-action related to existing architecture: "Not only is designing conducive to discoveries that prepare the student for further designing, but designing may be undertaken in order to build improved understandings of systems or structures." 20 The assertion that drawing can constitute "a means of coming to see things in new ways" is essentially equivalent to the PB hypothesis.

\subsection{The variability of the photographer's presence}

A comparison of two widely published photographs of Mies van der Rohe and Crown Hall illustrates the PB hypothesis within architectural photography. ${ }^{21}$ The first is a photograph of Mies standing over a model of Crown Hall, which appears to have been taken for publicity purposes. The image is clearly staged; Mies appears to be standing in front of a photographer's scrim. His arms are outstretched, presenting the model to his audience. The model appears as an extension of his own body - or perhaps it is his body which extends the architecture. The symmetry is arresting, the entire image being composed to reinforce it - except for Mies's slightly crooked tie, his handkerchief, and that in addition to the general light within the image there is also a light source outside of the frame, to Mies's left. It is this mutually constitutive relationship between designer and building which the photograph uniquely reveals. By contrast, the photograph of Mies smoking his cigar inside Crown Hall, taken shortly after the building's completion, appears accidental, as if the photographer between shots happened to catch Mies unaware. The photographer's presence is acutely forwarded by the slight departure from a true elevational view of the interior facade. The PB hypothesis suggests that photographs are uniquely capable of revealing the photographer's presence.

\section{Photography examined}

Each of the following sections is a review of work conducted by this paper's author inquiring into the degree to which the significance of a work of architecture is tied to the mediating artifacts. Because it has long been associated with the 
possibility of a neutral or transparent view of architecture photography is an obvious choice of medium within which to conduct this inquiry. ${ }^{22}$ Two cases are described: the first a description of process and the second a review of evidence. In both cases the question is the degree to which mediating artifacts (specifically photographs) are capable of uniquely identifying architectural significance. The cases are discussed in terms of both the Neutral Frame hypothesis and the Production Bias hypothesis. ${ }^{23}$

\subsection{Manipulating photography}

Rectification, or the distortion of original photographs from perspective into elevation view, proposes to remove an obvious bias from the original photographs: that of the photographer's station point and direction of view.24 The degree to which this bias remains present following rectification should reflect the degree to which photography as a medium is responsible for identifying a specific attribute of the subject architecture: an elimination of the photographer's bias would imply a transparent medium, indicating support for the NF hypothesis (i. e., that significant attributes of architecture can be communicated irrespective of the medium). By contrast, a failure of the rectified image to eliminate the photographer's bias lends support to the PB hypothesis.

To illustrate by example, consider a well-documented work of architecture, Mies van der Rohe's Crown Hall at IIT in Chicago. The graphical distortion of original photographs (Figures 1 and 3) into elevation oblique projections (Figures 2 and 4) is possible using simple techniques in Adobe Photoshop.

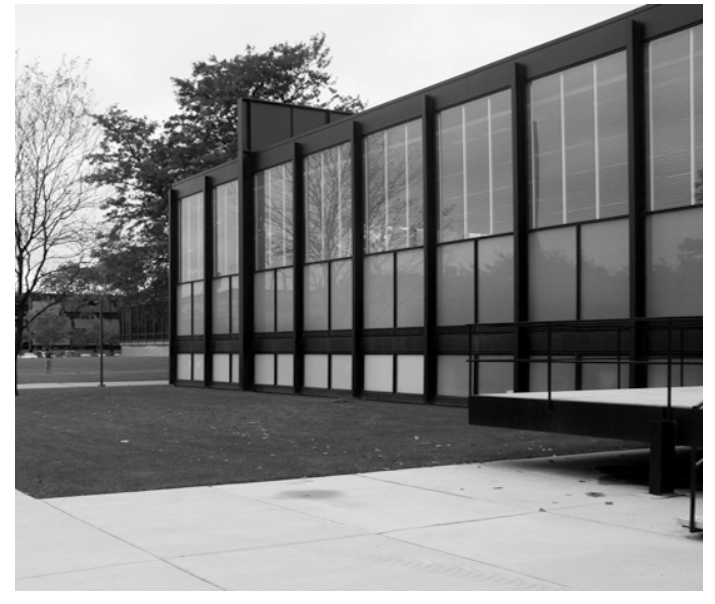

Figure 1: Crown Hall, IIT. Photograph by author.

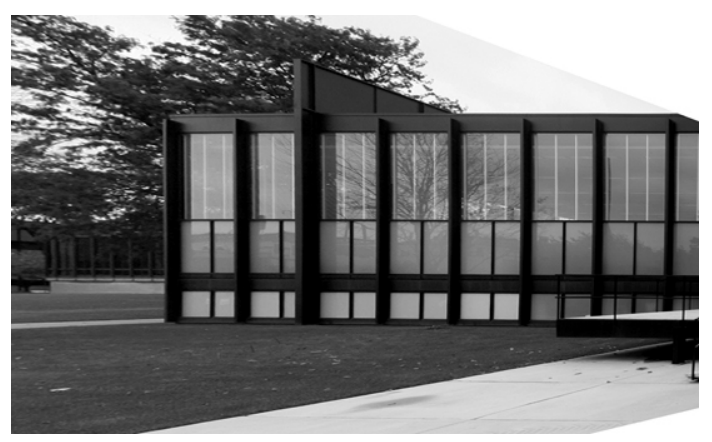

Figure 2: Manipulated copy of Figure 1: elevation oblique.

Shifting image projection from perspective into elevation appears to deny the relevance of the photographer's physical point of view: images which, when considered in series, revealed the photographer's movement around the building over time, are flattened through rectification. This initially appears to support the NF hypothesis, because visual information about the architecture appears unaffected by the medium. However, an inspection of the rectified images shows that although the building's glass facade is indeed visually flattened (i. e., removed from a perspective view), those parts of the architecture which project beyond the facade - such as the overhead trusses and their associated columns - are highlighted through distortion. The projections become the obvious exception to an otherwise neutrally composed facade. This visual effect - a simultaneous flattening and spreading of 
photographed depth - demonstrates that those attributes of a work of architecture the visibility of which are most dependent on a specific point of view are highlighted through deliberate flattening of the original images.

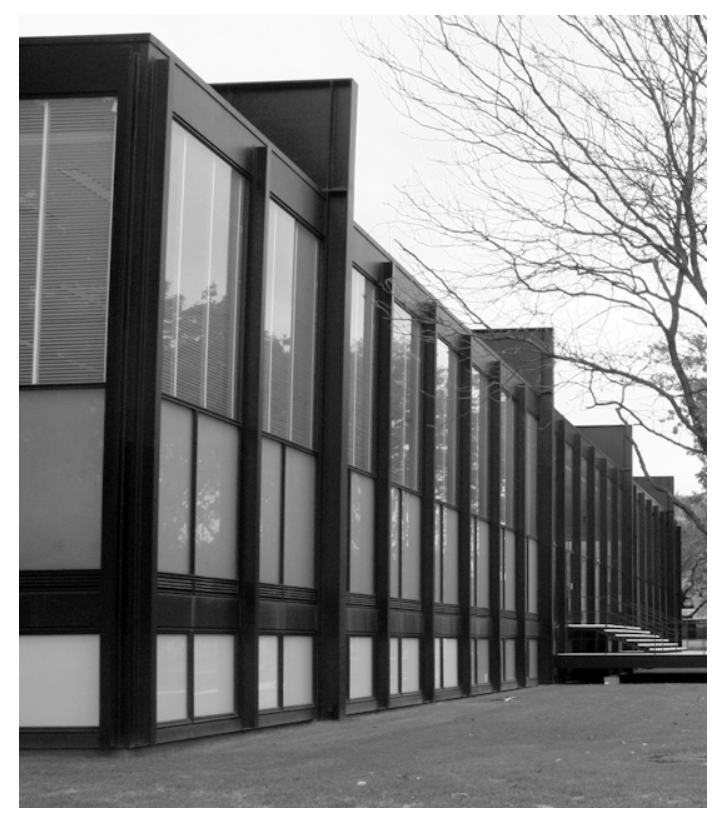

Figure 3: Crown Hall, IIT. Photograph by author.

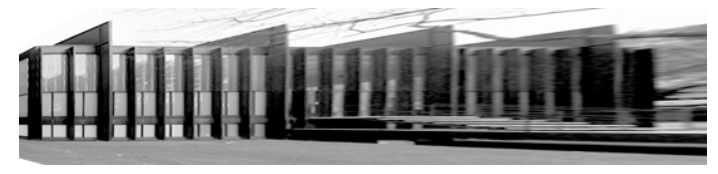

Figure 4: Manipulated copy of Figure 3: elevation oblique.

The observation that perception of Crown Hall's depth of elevation (i. e., its modeled or sculptural departure from a flat plane) depends on an observer's point of view is not obvious if attention is limited to the original, unmodified photographs. ${ }^{25}$ The NF hypothesis suggests that this observation is independent of the medium of communication; that it is characteristic of the architecture. However, this does not adequately explain why the observation was inobvious prior to conducting image distortion. The PB hypothesis better explains the observation because it assumes that media (e. g., photography, post-production modification of images) operate in distinct ways to reveal architectural attributes. In other words, the PB hypothesis appropriately recognizes the medium as the source of the observation of architectural significance.

\subsection{Spaces of photography}

It should be possible to compare different forms of media to discern their effect on architecture's "communicative potential." The NF hypothesis holds that the media through which a work of architecture is presented are incapable of distinguishing architectural significance: suggesting that a survey of the extant documentation of a work should not result in one form of medium providing a privileged or unique kind of understanding. Should a specific medium be shown instead to provide a unique form of understanding, the production bias hypothesis would provide a more appropriate framework for interpretation of the results.

Consider a set of photographs of Crown Hall in Werner Blaser's book on Crown Hall26 (Figure 5) as compared to a set of photographs of Crown Hall at Flickr.com, a publicly accessible online "photo management" application (Figure 6). ${ }^{27}$
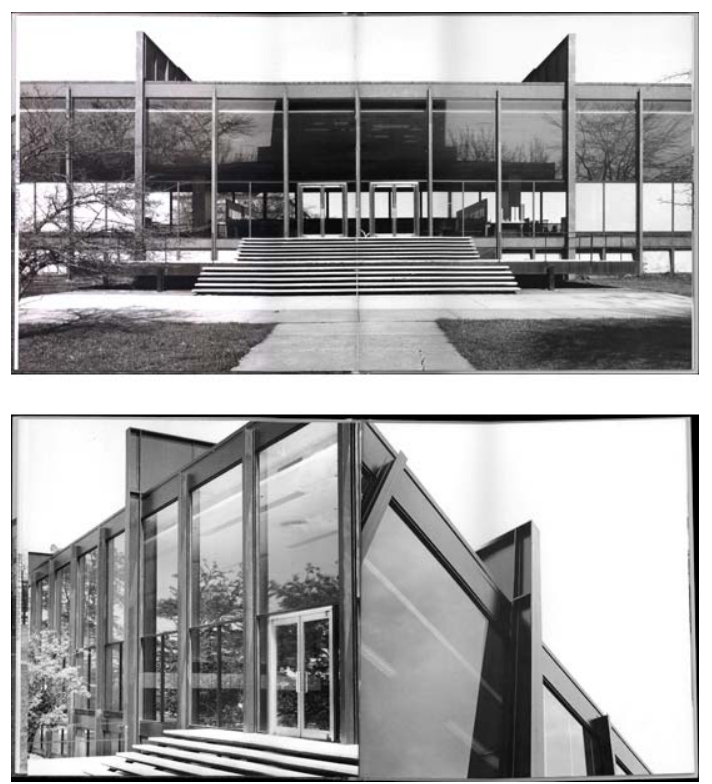

Figure 5: Examples of Werner Blaser's Crown Hall photographs. 

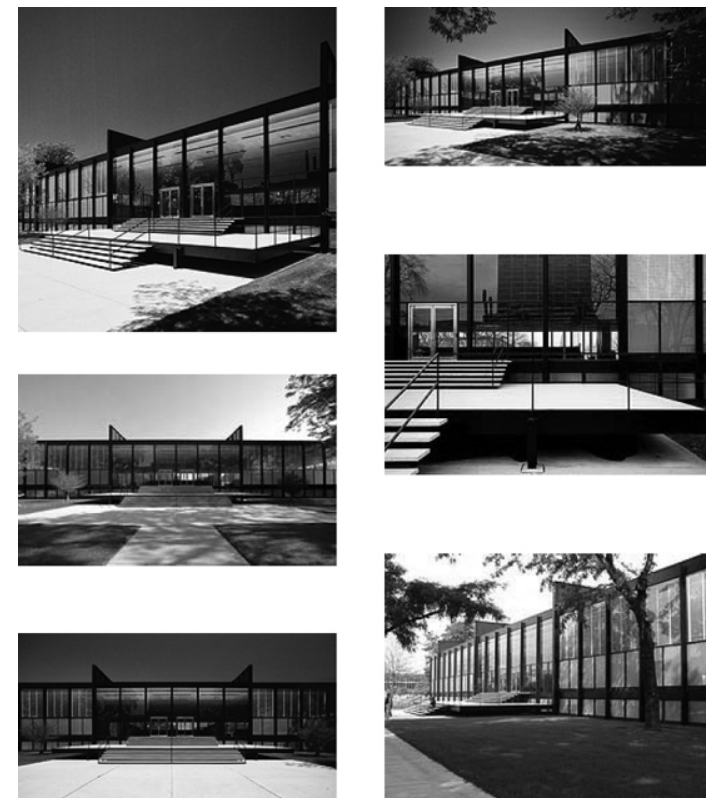

Figure 6: Examples of Crown Hall photographs resulting from a search conducted on Flickr.

Drawings of Crown Hall in plan and elevation illustrate the positions, points of interest, and fields of view of the photographs from each of the two sources (Figures 7 and 8). These drawings constitute a way of asking Where are the photographs being taken from? and What are people looking at? Figure 7 - recording the first twenty exterior image results from a Flickr search for Crown Hall - does not in any obvious way simulate the experience of visiting the building. Instead, it registers the visits of many people by describing a specific space of photography created by the superimposition of visitors' fields of vision. It indicates visitors' tendency to photograph the building from one side; indeed, not a single image in the first hundred Flickr image results was taken from a point where the front facade of Crown Hall was not visible. Figure 8 , by contrast, registers the purposeful visit of an individual photographer engaged in the production of a scholarly work. The space of photography in Figure 6 registers not only this attempt to document the building in an academically useful manner, but also by inference a process of editorial selection from which several candidate images were certainly removed.

By revealing the difference between the production of a scholarly work and the ad hoc assembly characteristic of Flickr, Figures 7 and 8 reflect genuinely different views on how architecture should be seen, should be remembered, should be understood and should be learned about. This suggests that researchers or students using Flickr will arrive at very different conclusions about Crown Hall's architectural significance than those reading Blaser's book, even if all they do is inspect the photographs. If, as the NF hypothesis suggests, the architectural significance of Crown Hall is truly independent of the medium through which the significance is communicated, then Figure 7 should exhibit a structure like Figure 8 , with points-of-view evenly distributed rather than weighted to one side. The PB hypothesis explains the different structures because it assumes that each medium necessarily makes the architecture visible in fundamentally different ways. The purpose of the photographs in Blaser's book is to forward a scholarly point of view, tempered by a "top-down" editorial process. By comparison, while Flickr is deliberately "bottomup," non-hierarchical and equivocal, it nevertheless clearly reflects the motivations of tourists interested in publishing their photographic contributions for public access. ${ }^{28}$ Does architecture communicate the same message to the scholar as to the tourists? It is at least clear that the scholarly medium and the touristic medium convey very different messages about the architecture. 

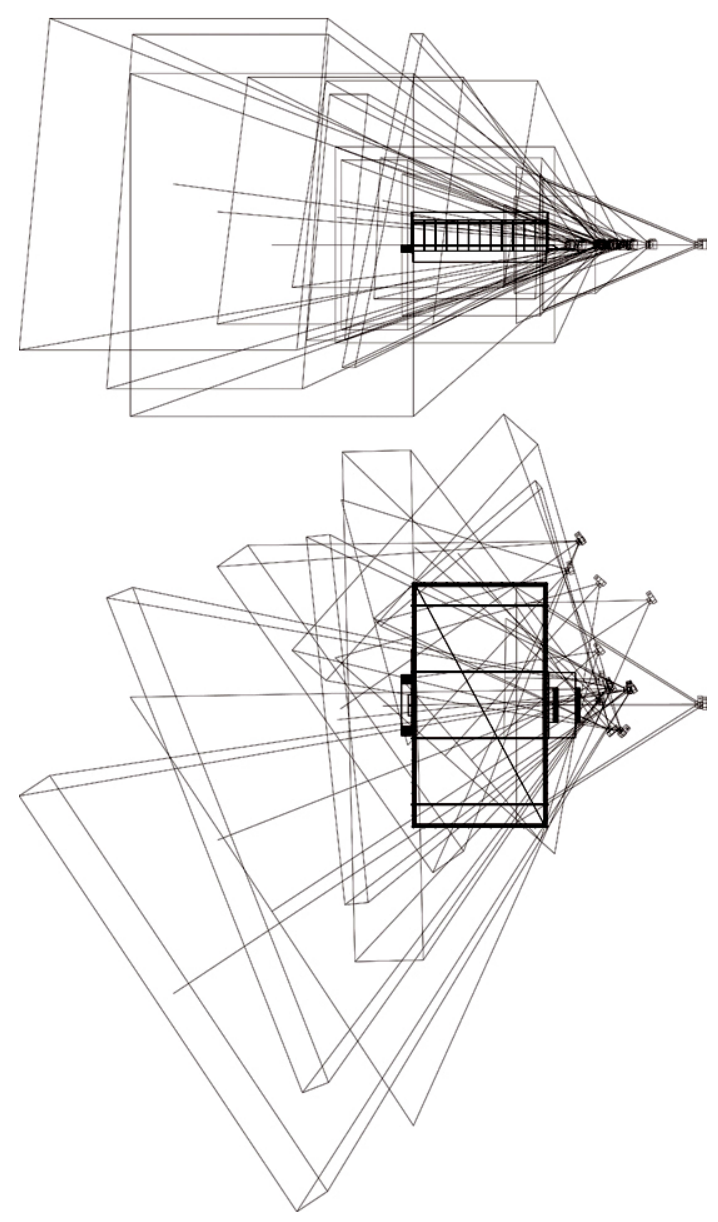

Figure 7. Locations of Flickr photographs of Crown Hall, superimposed on section (top) and plan (bottom). Note the generally one-sided distribution of station points and fields of view.
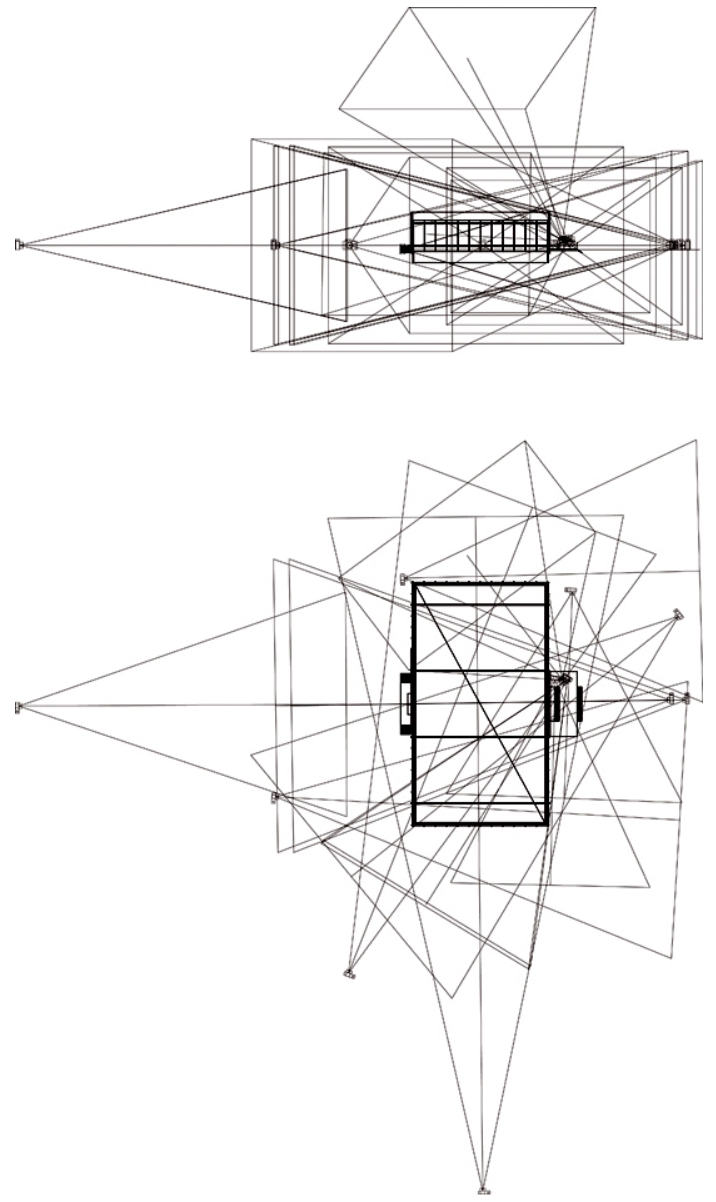

Figure 8. Locations of W. Blaser's photographs of Crown Hall, superimposed on section (top) and plan (bottom). Note the generally well-distributed station points and fields of view.

\section{Conclusions}

The above discussions suggest that a specific medium can be used to uniquely discern specific architectural attributes, whether these attributes are formal, such as Crown Hall's depth of elevation, or related to documentary sources, such as the different spaces of photography made possible by Crown Hall. But the discussions also incidentally suggest that architecture can become a means for learning about media: specifically, by illustrating that AutoCAD's disciplinary usefulness need not be focused primarily to the production of construction documents, nor Photoshop's to the production of strictly photorealistic images. As architecture's communicative potential is further explored it is imperative that architectural 
media be allotted their proper role: media are necessary to engage architecture's communicative potential.

\section{Notes}

1. W. L. Porter, "Designers' objects," in Design Representation, ed. G. Goldschmidt and W. L. Porter, 63-79 (London: Springer, 2004), 64 .

2. The author acknowledges the anonymous reader of this paper who commented on the analytic/synthetic distinction.

3. "The question driving the debate is whether media such as computers and television are able to influence the learning of anything, by anyone, anywhere." See R. E. Clark (ed.), Learning from Media (Greenwich, Connecticut: Information Age Publishing, 2001), ix. Robert Kozma, Clark's antagonist in the "media-methods debate," summarized his arguments in two major papers [R. B. Kozma, "Learning with media," Review of Educational Research 61, no. 2 (1991): 179-212, and R. B. Kozma, "Will media influence learning? Reframing the debate," Educational Technology Research and Development 42, no. 2 (1994): 7-19]. See Section 3.1 of this paper for more on Kozma's views.

4. R. E. Clark, "Reconsidering research on learning from media," Review of Educational Research 53, no. 4 (1983): 445.

5. R. E. Clark, "Media will never influence learning," Educational Technology Research \& Development 42, no. 2 (1994): 22-23.

6. R. H. Clark and M. Pause. Precedents in Architecture (New York: Van Nostrand Reinhold, 1995), vii.

7. The categories in the original edition of Precedents in Architecture are: "structure," "plan to section," "repetitive to unique," "symmetry and balance," "natural light," "circulation to use-space," "massing," "unit to whole," "geometry," "additive and subtractive," and "hierarchy." Clark and Pause, Precedents in Architecture, xi.

8. Obvious variations within the general framework exist in the "factual sheets" accompanying each set of diagrams. The "factual sheets" present varying types of documentation: sometimes one section or elevation is shown; sometimes two. Also, instances occur where two or more diagrams for a given building are identical (e. g., several buildings are given identical diagrams for "unit to whole" and "additive and subtractive"). It is possible that this internal repetition reflects the later addition of a category to an initial set.

9. "The ability to doctor photographs by adding, subtracting, multiplying, or substituting things has been with us since the beginning of photography. It has now not only accelerated with digital photography, but has become nearly impossible to detect ... Even a battery of experts can disagree on the truth of a photograph." [M. R. Peres (ed.), The Focal Encyclopedia of Photography: Digital Imaging, Theory and Applications, History, and Science (Amsterdam, Boston: Elsevier/Focal Press, 2007), 468.] On the traditions of photographic fakery, see E. Martin, "Against photographic deception," Journal of Mass Media Ethics 2, no. 2 (1987): 49-59; on changes in practices due to the advent of digital technology, see E. Martin, "On photographic manipulation," Journal of Mass Media Ethics 6, no. 3 (1991):
156-163.

10. A. S. Zion, "New modern: Architecture in the age of digital technology," Assemblage 35 (1998): 70.

11. J. Bermudez and K. King, "Media interaction and design process: Establishing a knowledge base," Automation in Construction 9, no. 1 (2000): 41.

12. Selected instances from the past thirty years of literature reinforcing this idea include Michael Graves's description of the "insistence" of drawing [M. Graves, "The necessity of drawing: tangible speculation," Architectural Design 47 (1977): 384], Nancy Cheng's statement with regard to architectural design that "certain ideas will only emerge with specific tools" [N. Cheng, "By all means: Multiple media in design education," in Multimedia and Architectural Disciplines (Proceedings of the 13th European Conference on Education in Computer Aided Architectural Design in Europe), ed. B. Colajanni, et al, 117-128 (Palermo, Italy: Dipartimento di Progetto e Costruzione Edilizia, 1995)], and Mario Carpo's acknowledgment that the Renaissance "shift from words to pictures had a decisive effect on the whole process of architectural design" [M. Carpo, "How do you imitate a building that you have never seen? Printed images, ancient models, and handmade drawings in renaissance architectural theory," Zeitschrift für Kunstgeschichte 64, no. 2 (2001): 227].

13. M. Hewitt, "Representational forms and modes of conception: An approach to the history of architectural drawing," Journal of Architectural Education 39, no. 2 (1985): 9.

14. N. A. Crowe and S. W. Hurtt, "Visual notes and the acquisition of architectural knowledge," Journal of Architectural Education 39, no. 3 (1986): 12.

15. D. Leatherbarrow, "Showing what otherwise hides itself," Harvard Design Magazine 6 (1998): 51-52.

16. I. Borden, "Imaging architecture: The uses of photography in the practice of architectural history," The Journal of Architecture 12, no. 1 (2007): 61.

17. Kozma, "Will media influence learning?" 7-19.

18. B. Zevi, Architecture as Space, Rev. ed. (New York: Horizon Press, 1974), 45-60. Zevi proposes an increased use of film on the assumption that its verisimilitude will provide a better representation of existing architecture: "[l]t seems likely that in teaching the history of architecture, the use of films, rather than of books, will greatly advance general spatial education." (Zevi, Architecture as Space, 59.)

19. Site contours are discussed in D. A. Schön, The Reflective Practitioner: How Professionals Think in Action (New York: Basic Books, 1983), 82, 93-94, 130-136, 157-159; D. A. Schön, "The architectural studio as an exemplar of education for reflection-in-action," Journal of Architectural Education 38, no. 1 (1984): 4-5; D. A. Schön, The Design Studio: An Exploration of its Traditions and Potentials (London: RIBA Publications Limited, 1985); D. A. Schön, Educating the Reflective Practitioner (San Francisco: Jossey-Bass, 1987), 46-49, 74-76; and D. A. Schön, "Toward a marriage of artistry and applied science in the architectural design studio," Journal of 
Architectural Education 41, no. 4 (1988): 8. The Library Entrance exercise is discussed in Schön \& Wiggins, "Kinds of seeing and their functions in designing," 145-154. Apart from the examples cited here, Schön occasionally hints at the possibilities of reflection-in-action as these might relate to existing architecture, as for example when he identifies (but does not elaborate on) the Design Domain of precedent, ascribing it no unique consequences; or, as in Schön, "Toward a marriage of artistry and applied science in the architectural design studio," where he speculates on the value of architectural types.

20. Schön and Wiggins, "Kinds of seeing and their functions in designing," 155.

21. As of May 2008, the first image could be found in lowresolution format at the following URL:

http://www.iit.edu/publications/contact/images/ photos/mies1.jpg.

and the second image at the following URL:

http://mies.iit.edu/about/images/mies_in_crown.jpg.

22. "Photography is the largely unquestioned, primary medium of architectural reportage." R. Wilson, "At the limits of genre: Architectural photography and utopic criticism," Journal of Architecture 10 (2005): 265.

23. Production details for the images in this paper are as follows: Figures 1 and 3 are the author's original photographs; Figures 2 and 4 were modified from the author's original photographs using Adobe Photoshop CS2; Figure 5 consists of scans from W. Blaser, Mies van der Rohe: Crown Hall (Basel: Birkhauser, 2001), 30-31, 36-37; Figure 6 is a screenshot from Flickr (see note 27, below); Figures 7 and 8 were produced from the author's three-dimensional AutoCAD model of Crown Hall, modified in Adobe Illustrator CS2 and Adobe Photoshop CS2.

24. This discussion extends work completed by the paper's author in 2007 [M. Christenson, "Ownership and media: The architectural case study as an articulation of theoretical stance," in Flow, Filter, Function, Feeling, and Focus (Proceedings, Design Communication Association 20th Anniversary Conference, 12-15 September 2007, Ball State University), edited by M. A. Mounayar, G. T. Cruz, and C. Bove, 251-252].

25. However, the modified photographs provide a new basis by which to conduct inquiry into the original images. This recalls Crowe \& Hurtt's observation about the similarity between analysis and design (Crowe and Hurtt, "Visual notes and the acquisition of architectural knowledge," 12).

\section{Blaser, Mies van der Rohe.}

27. The search was conducted on Flickr.com in April 2008 using the term "crown hall" (quotes included). The search resulted in 628 images, most of which were exterior images of the building, and several of which were not related in any direct way to the building. Figure 7 locates the points of view, directions of view, and fields of view of the first twenty exterior images of Crown Hall resulting from the search.
28. An anonymous reader of this paper suggested the distinction between the "top-down" control over content evident with Blaser's book and the "bottom-up" control of content evident with Flickr. 


\section{Bibliography}

Bermudez, J. and K. King. "Media interaction and design process: Establishing a knowledge base." Automation in Construction 9, no. 1 (2000): 37-56.

Blaser, W. Mies van der Rohe: Crown Hall. Basel: Birkhauser, 2001.

Borden, I. "Imaging architecture: The uses of photography in the practice of architectural history." The Journal of Architecture 12, no. 1 (2007): 57-77.

Carpo, M. "How do you imitate a building that you have never seen? Printed images, ancient models, and handmade drawings in renaissance architectural theory." Zeitschrift für Kunstgeschichte 64, no. 2 (2001): 223-233.

Cheng, N. "By all means: Multiple media in design education," in Multimedia and Architectural Disciplines (Proceedings of the 13th European Conference on Education in Computer Aided Architectural Design in Europe), edited by B. Colajanni, et al, 117-128. Palermo, Italy: Dipartimento di Progetto e Costruzione Edilizia, 1995.

Christenson, M. "Ownership and media: The architectural case study as an articulation of theoretical stance," in Flow, Filter, Function, Feeling, and Focus (Proceedings, Design Communication Association 20th Anniversary Conference, 1215 September 2007, Ball State University), edited by M. A. Mounayar, G. T. Cruz, and C. Bove, 247-258.

Clark, R. E. "Media will never influence learning." Educational Technology Research \& Development 42, no. 2 (1994): 21-29.

---. "Reconsidering research on learning from media." Review of Educational Research 53, no. 4 (1983): 445-459.

---. (ed.) Learning from Media. Greenwich, Connecticut: Information Age Publishing, 2001.

Clark, R. H., and Michael Pause. Precedents in architecture. New York: Van Nostrand Reinhold, 1995.

Crowe, N. A., and S. W. Hurtt. "Visual notes and the acquisition of architectural knowledge." Journal of Architectural Education 39 , no. 3 (1986): 6-16.

Graves, M. "The necessity of drawing: tangible speculation." Architectural Design 47 (1977): 384-394.

Hewitt, M. "Representational forms and modes of conception: An approach to the history of architectural drawing." Journal of Architectural Education 39, no. 2 (1985): 2-9.

Kozma, R. B. "Learning with media." Review of Educational Research 61, no. 2 (1991): 179-212.

---. "Will media influence learning? Reframing the debate." Educational Technology Research and Development 42, no. 2 (1994): 7-19.

Leatherbarrow, D. "Showing what otherwise hides itself." Harvard Design Magazine 6 (1998): 51-55.

Martin, E. "Against photographic deception." Journal of Mass
Media Ethics 2, no. 2 (1987): 49-59.

---. "On photographic manipulation." Journal of Mass Media Ethics 6, no. 3 (1991): 156-163.

Peres, M. R. (ed.) The Focal encyclopedia of photography: digital imaging, theory and applications, history, and science. Amsterdam, Boston: Elsevier/Focal Press, 2007.

Porter, W. L. "Designers' objects," in Design Representation, edited by G. Goldschmidt and W. L. Porter. 63-79. London: Springer, 2004.

Schön, D. A. The reflective practitioner: How professionals think in action. New York: Basic Books, 1983.

---. "The architectural studio as an exemplar of education for reflection-in-action." Journal of Architectural Education 38, no. 1 (1984): 2-9.

---. The Design Studio: An Exploration of its Traditions and Potentials. London: RIBA Publications Limited, 1985.

---. Educating the Reflective Practitioner. San Francisco: Jossey-Bass, 1987.

---. "Toward a marriage of artistry and applied science in the architectural design studio." Journal of Architectural Education 41 , no. 4 (1988): 4-10.

Schön, D. A., and G. Wiggins. "Kinds of seeing and their functions in designing." Design Studies 13, no. 2 (1992): 135156.

Wilson, R. "At the limits of genre: Architectural photography and utopic criticism." Journal of Architecture 10 (2005): 265-273.

Zevi, B. Architecture as Space. New York: Horizon Press, 1957 (1974 reprint).

Zion, A. S. "New modern: Architecture in the age of digital technology." Assemblage 35 (1998): 62-79 